\title{
Pathophysiological Underpinnings of Multiple Myeloma Progression
}

\author{
Sundar Jagannath, MD
}

\begin{abstract}
BACKGROUND: Multiple myeloma (MM) is a malignant neoplasm of plasma cells that accumulate in the bone marrow. Myeloma is characterized by skeletal destruction, renal failure, hypercalcemia, and anemia. Currently, there is no cure, though recent understanding of the bone marrow microenvironment and the cytogenetics involved in MM are leading to improved and individualized treatment strategies, leading to longer periods of remission and improved survival rates.
\end{abstract}

OBJECTIVE: To review MM pathophysiology, genetic issues, other risk factors, and the steps of disease progression. This section will address diagnosis, staging, classification, and disease complications, as well as the roles of cytogenetic abnormalities and the bone marrow milieu.

SUMMARY: In MM, malignant plasma cells in the in the bone marrow produce large quantities of monoclonal protein (M protein) leading to stimulation of osteoclasts. This increase in osteoclast activity leads to bone resorption and destruction, causing painful bone lesions and hypercalcemia. Myeloma cells also crowd out other normal bone marrow cells, which leads to a plethora of complications, including renal insufficiency, anemia, infection, and clotting disorders.

Updated standards of diagnosis, staging, and classification of MM have recently been developed. The International Staging System (ISS) categorizes myeloma patients into 1 of 3 groups based on serum albumin and beta2-microglobulin blood tests.

Genetic mutations leading to chromosomal translocations and deletions play a key role in the progression to active, malignant MM. Cytogenetic testing allows physicians to appropriately diagnose and treat patients specific to their unique presentation of disease.

CONCLUSION: The future of treating the myeloma patient is progressing at a fast and positive pace. Identification and treatment of comorbid conditions are leading to improvements in quality of life. Identification of potential therapeutic targets in the bone marrow microenvironment is leading to the development of therapies that are changing the standard of care for MM patients.

J Manag Care Pharm. 2008;14(7)(suppl S):S7-S11

Copyright@ 2008, Academy of Managed Care Pharmacy. All rights reserved.

Author

SUNDAR JAGANNATH, MD, is Chief, Multiple Myeloma and

Transplant Program, St. Vincent's Comprehensive Cancer Center,

Professor of Medicine, New York Medical College, New York, New York.

AUTHOR CORRESPONDENCE: Sundar Jagannath, MD, Professor

of Medicine, New York Medical College, New York, NY 10011

Tel.: 212.604.6068; Fax: 212.604.6059;

E-mail: sjagannath@aptiumoncology.com

\section{General Overview and Pathophysiology of Multiple Myeloma}

In the normal human, hematopoietic stem cells give rise to B lymphocytes in the bone marrow, which then circulate in the blood and home to the lymph nodes where they undergo antigen selection. Antigen-selected B lymphocytes capable of producing immunoglobulin $\mathrm{M}$ antibodies undergo isotype switching and differentiate into immunoglobulin G- or A-producing plasma cells. Normal plasma cells predominantly reside in the bone marrow, and adhere to the stromal cells and produce immunoglobulins.

In multiple myeloma (MM), genetic damage occurs in the developing B lymphocyte at the time of isotype switching, thus transforming the normal plasma cell into a malignant MM cell. These malignant cells arise from a single clone, multiply in the bone marrow, crowd normal bone marrow cells, and produce large quantities of monoclonal immunoglobulin (M) protein. Malignant plasma cells stimulate osteoclasts that cause bone resorption and inhibit osteoblasts that form new bone in the immediate vicinity, causing lytic bone lesions. These lesions are the hallmark of MM. Hypercalcemia is observed due to the increase in osteoclast activity. ${ }^{1}$

In the early stages of MM, symptoms are often vague or similar to other conditions. Symptoms may include bone pain, weakness, fatigue, or infection. Loss of appetite, restlessness, increased urination, confusion, polyuria, nausea, and vomiting may occur due to hypercalcemia. Diagnostic tests to confirm a diagnosis of myeloma must be performed, including tests on blood, urine, bone, and bone marrow. ${ }^{1}$

In addition to its effect on the normal process of bone repair and growth, MM may also affect the blood and kidneys. The increases in $\mathrm{M}$ protein and calcium in the blood may overtax the kidneys, leading to reduced function and/or failure. As myeloma cells proliferate uncontrollably, they impact production of all types of blood cells negatively. Anemia may occur due to the reduction in red cells, and the reduction in platelets can result in bleeding. There is increased risk of infection due to inability to produce antibodies and a decrease in white blood cells. The high levels of $\mathrm{M}$ protein increase serum viscosity and may also affect coagulability. Therefore, venous thromboembolism (VTE) is also a serious risk for MM patients. ${ }^{1}$

The first pathogenetic step in the development of myeloma is the emergence of a limited number of clonal plasma cells, clinically known as monoclonal gammopathy of undetermined significance (MGUS). ${ }^{2}$ MGUS is characterized by serum M protein level less than $3 \mathrm{gm}$ per $\mathrm{dL}$, bone marrow clonal plasma cells less than $10 \%$, and no evidence of other B-cell disorders. ${ }^{1}$ Patients with MGUS do not have symptoms or evidence of end-organ damage, but do have a risk of $1 \%$ per year for progression to $\mathrm{MM}$ or a related malignant disease. ${ }^{1,2}$ MGUS is not a malignant condition 


\begin{tabular}{|c|c|c|c|}
\hline Stage & Durie-Salmon Criteria & ISS Criteria & $\begin{array}{l}\text { Median } \\
\text { Survival } \\
\text { (Months) }\end{array}$ \\
\hline I & $\begin{array}{l}\text { All of the following: } \\
\text { - Hemoglobin value }>10 \mathrm{gm} \\
\text { per dL } \\
\text { - Serum calcium value normal } \\
\text { or } \leq 12 \mathrm{mg} \text { per dL } \\
\text { - Bone X-ray, normal bone } \\
\text { structure (scale 0), or solitary } \\
\text { bone plasmacytoma only } \\
\text { - Low M-component production } \\
\text { rate: IgG value }<5 \text { gm per dL; } \\
\text { IgA value }<3 \text { gm per dL } \\
\text { - Bence Jones protein }<4 \text { gm } \\
\text { per } 24 \text { hour }\end{array}$ & $\begin{array}{l}\beta_{2}-\mathrm{M}<3.5 \mathrm{mg} \\
\text { per } \mathrm{dL} \text { and } \\
\text { albumin } \geq 3.5 \mathrm{gm} \\
\text { per } \mathrm{dL}\end{array}$ & 62 \\
\hline$\overline{\mathrm{II}^{\mathrm{b}}}$ & Neither stage I nor stage III & $\begin{array}{l}\text { Neither stage I } \\
\text { nor stage III }\end{array}$ & 44 \\
\hline III & $\begin{array}{l}\text { 1 or more of the following: } \\
\text { - Hemoglobin value < } 8.5 \mathrm{gm} \\
\text { per } \mathrm{dL} \\
\text { - Serum calcium value }>12 \mathrm{mg} \\
\text { per dL } \\
\text { - Advanced lytic bone lesions } \\
\text { (scale } 3 \text { ) } \\
\text { - High } \mathrm{M} \text {-component production } \\
\text { rate: IgG value }>7 \text { gm per dL; } \\
\text { IgA value }>5 \text { gm per } \mathrm{dL} \text {; } \\
\text { - Bence Jones protein }>12 \mathrm{gm} \\
\text { per } 24 \text { hour }\end{array}$ & $\begin{array}{l}\beta_{2}-\mathrm{M} \geq 5.5 \mathrm{mg} \\
\text { per } \mathrm{dL}\end{array}$ & 29 \\
\hline
\end{tabular}

a Multiple Myeloma Research Foundation; 2006; 1 and Orlowski RZ, Hematology Am Soc Hematol Educ Program; 2006. 10

b Stage $I I=\beta_{2}-M<3.5 \mathrm{mg}$ per $d L$ or $\beta_{2}-M=3.5-5.5 \mathrm{mg}$ per $d L$, and albumin $<3.5$ gm per $d L$

but is considered to be a precursor to myeloma, with MM subsequently developing in up to $20 \%$ of individuals. No immediate treatment is necessary for MGUS; patients are observed regularly for disease progression. ${ }^{1}$

The second category is asymptomatic or smoldering multiple myeloma, which is characterized by serum $\mathrm{M}$ protein greater than or equal to $3.0 \mathrm{gm}$ per $\mathrm{dL}$ and/or bone marrow plasma cells greater than or equal to $10 \%$. As with MGUS, there are no symptoms, or related organ or tissue impairment. The annual risk of progression to malignancy is $10 \%-20 \%{ }^{1}$ The median time from the diagnosis of asymptomatic or smoldering multiple myeloma to the progression of symptomatic MM is 2-3 years. Risks outweigh the benefit for starting treatment early for many, and some patients may remain progression-free for several years. Early treatment intervention must be evaluated on a case-by-case basis, and patients should be encouraged to participate in clinical trials.
The stages of MM are distinguished by the amount of tumor cells in the body, their proliferation rate, and the patient's symptoms. Normal plasma cells, as well as MGUS and MM cells, depend on the bone marrow microenvironment for survival, growth, and differentiation. These processes are, in part, mediated by paracrine interleukin-6 (IL-6) and insulin-like growth factor 1. The evolving interaction of MM cells with the bone marrow microenvironment is also involved in the secondary effects of malignancy, including osteolysis, anemia, and immunodeficiency. ${ }^{2,3}$

\section{Diagnosis, Staging, and Classification}

Symptomatic myeloma is characterized by elevated M protein in serum and/or urine, bone marrow clonal plasma cells or plasmacytoma (a single tumor in the bone or soft tissue comprising malignant plasma cells), and related organ or tissue impairment. Symptomatic myeloma requires immediate treatment. ${ }^{1}$ The clinical manifestations of end-organ damage that meets the criteria for the diagnosis of MM consists of a group of findings referred to as $\mathrm{CRAB}:{ }^{4}$

- HyperCalcemia (serum calcium level greater than $0.25 \mathrm{mmol}$ per $\mathrm{L}$ above the upper limit of normal, or greater than $2.75 \mathrm{mmol}$ per L, or greater than $11.0 \mathrm{mg}$ per $\mathrm{dL}$ )

- Renal insufficiency (creatinine level greater than $173 \mathrm{mmol}$ per L or greater than $1.9 \mathrm{mg}$ per $\mathrm{dL}$ )

- Anemia (hemoglobin level of 2.0 gm per dL below the lower limit of normal or less than $10 \mathrm{gm}$ per $\mathrm{dL}$ )

- Bone lesions (lytic bony lesions or osteoporosis with compression fractures) ${ }^{4}$

The most widely used staging system for determining risk and prognosis since 1975 has been the Durie-Salmon Staging System. This staging system categorizes patients into 1 of 3 categories (stage I, II, or III) based on hemoglobin level, serum calcium level, the production rate of $\mathrm{M}$ protein, and the number of osteolytic lesions. ${ }^{1}$ Stages are further divided according to renal function and subclassified as A or B. Subclass A is relatively normal renal function (serum creatinine value less than $2.0 \mathrm{mg}$ per $\mathrm{dL}$ ) and subclass B is abnormal renal function (serum creatinine value greater than or equal to $2.0 \mathrm{mg}$ per $\mathrm{dL}$ ). The International Staging System (ISS) is a newer, more accurate system and has 3 stages based solely on results of serum albumin and beta $2_{2}$ microglobulin blood tests. Taken together, the results of these 2 tests, among other tests, have been shown to provide the most accurate prediction of how the disease will respond to treatment. ${ }^{1}$ The ISS was developed after a multivariate analysis of parameters that were predictive of survival in more than 10,750 patients worldwide ${ }^{5}$ (Table 1).

\section{The Role of the Bone Marrow Microenvironment in Multiple Myeloma}

The microenvironment of the bone marrow consists of various extracellular matrix (ECM) proteins, including fibronectin, 
collagen, laminin, and osteopontin. Other cell components include hematopoietic stem cells, progenitor and precursor cells, immune cells, erythrocytes, bone marrow stromal cells (BMSCs), bone marrow endothelial cells, osteoclasts, and osteoblasts. The interaction of MM cells with the extracellular matrix proteins and accessory cells in the bone marrow milieu plays a crucial role in MM pathogenesis. The direct interactions of MM cells with accessory cells and secreted cytokines activate signaling pathways mediating growth, survival, drug resistance, and the migration of MM cells, as well as osteoclastogenesis and angiogenesis. ${ }^{6}$

Increased expression of the receptor activator of nuclear factor-kappaB (NF-kappaB) ligand (RANKL) and a reduction in the level of its decoy receptor by osteoblasts are thought to cause the development of bone lesions due to bone resorption caused by the activation of osteoclasts. Overexpression of RANKL is probably mediated in part by the release of macrophage inflammatory protein lalpha (MIP-lalpha) by neoplastic plasma cells. ${ }^{7}$ Cytokine pathways responsible for both osteoclast stimulation and osteoblast inhibition have been studied and have greatly improved understanding of myeloma bone disease. Tumorstromal cell interactions via adhesion molecules (VCAM-1) result in the release of not only RANKL, but also many other cytokines, including IL-6, MIP-lalpha, and tumor necrosis factor-alpha (TNF-alpha), which increase the production of osteoclastic factors, and Dickkopf 1, which inhibits osteoblasts. Additionally, clinical associations with biochemical markers of bone disease and the ability to select patients who are more likely to respond well to bisphosphonates have been documented. ${ }^{8}$

\section{The Role of Cytogenetics}

Cytogenetics, or the study of chromosomes during cell division, can be used to tailor treatment in MM. With the progression from MGUS to symptomatic myeloma, complex genetic events occur in the neoplastic plasma cell. Genomic instability, including translocations in heavy-chain immunoglobulin switch region at position $14 \mathrm{q} 32$ and overexpression of cyclin $\mathrm{D}$ are considered pathogenetic in this disease. ${ }^{2,9}$ It is now known that MM can be subdivided into 2 groups based on the pattern of chromosomal aberrations. Approximately 55\%-60\% of patients have a hyperdiploid karyotype; the remaining cases are classified as the nonhyperdiploid group, or hypodiploid. Recent studies have proposed further subclassifications of the 2 groups and may lead to a better understanding of prognosis and more individualized treatment plans. Patients with hyperdiploid MM tend to have a better prognosis. Patients presenting with $t(14 ; 16)$ and $t(4 ; 14)$ translocations have a poor prognosis, whereas patients presenting with $t(11 ; 14)$ have a longer survival relative to all other genetic subtypes $^{6}$ (Table 2). Cytogenetic information clearly provides important prognostic information. For example, patients with a 4;14 translocation, resulting in overexpression of fibroblast growth factor receptor 3 (FGFR-3), have been reported to have an approximately 8-month median time to progression after an

\begin{tabular}{l|l|c}
\hline TABLE 2 & $\begin{array}{l}\text { Possible Cytogenetics-Based } \\
\text { Prognostic Groupinga }\end{array}$ \\
\hline Risk Group & Cytogenetics & $\begin{array}{c}\text { Median Overall } \\
\text { Survival (Months) }\end{array}$ \\
\hline Poor & $\mathrm{t}(4 ; 14), \mathrm{t}(14 ; 16)$, & 24.7 \\
\hline Intermediate & $-17 \mathrm{p} 13$ & 42.3 \\
\hline Good & $-13 \mathrm{ql} 14$ & 50.5 \\
\hline
\end{tabular}

a Orlowski RZ, Hematology Am Soc Hematol Educ Program; 2006.10

autologous stem cell transplant. Similarly, deletion of chromosome 13 (del 13) appears to suggest a poor prognosis. Agents that focus on overcoming the impact of del 13 would be advantageous for patients in this subset. ${ }^{10}$

Although detection of abnormal karyotypes by conventional metaphase cytogenetics is helpful in prognosis, the yield is low, around $30 \%$. Besides, certain cryptic translocations, such as $\mathrm{t}(4 ; 14)$ or $\mathrm{t}(14 ; 16)$, are not detectable by conventional cytogenetics. Therefore, interphase fluorescence in situ hybridization (FISH) probing for known abnormalities should always supplement cytogenetics in MM. ${ }^{11}$

\section{Risks Associated With Multiple Myeloma}

\section{Venous Thromboembolism}

Patients with MM are at high risk for developing deep vein thrombosis and VTE, with reported incidences of up to 30\%, especially in patients receiving multiagent chemotherapy and antiangiogenic drugs. ${ }^{12}$ Protein $\mathrm{S}$ is a vitamin K-dependent glycoprotein involved in the anticoagulation pathway. One study looked at protein $S$ levels and found that those levels decreased significantly with increasing ISS stage. Lower levels of protein $S$ may increase the risk of thromboembolic complications in the more severe stages of $\mathrm{MM}$, because protein $\mathrm{S}$ deficiency is known to be associated with VTE. The same study also measured coagulation factors factor VIII (FVIII) and von Willebrand factor (vWF). A correlation between disease stage and levels of FVIII and $\mathrm{vWF}$ was demonstrated and found to be highest in stage III. The pathogenetic mechanism of the increased levels of FVIII and vWF is unclear, but may be related to neovascularization in the bone marrow stroma. However, the study determined that no single prothrombotic abnormality can be used to predict which patients will develop VTE. ${ }^{13}$

\section{Skeletal Lesions}

The development of osteolytic lesions in myeloma is secondary to bone resorption by increased activity of osteoclasts, accompanied by decreased osteoblast function. One focus of myeloma research revolves around the signaling pathways involved in osteoclast and osteoblast function, as well as the identification of targets for therapy to prevent and treat bone disease. ${ }^{14}$ 


\section{Renal Insufficiency}

At diagnosis, approximately 20\% of patients have renal insufficiency. Over the course of the disease, up to 50\% will show renal dysfunction., ${ }^{4}$, Volume depletion, infection, and nonsteroidal inflammatory agents (NSAIDs) used for pain may contribute to renal failure, as do hypercalcemia, and amyloidosis. NSAIDs and contrast media should be avoided whenever possible in these patients. Patients with MM who have high urinary levels of Bence Jones proteins, or "light chains" (approximately $18 \%-25 \%$ of MM cases) are at higher risk of significant renaldamage, including complete loss of kidney function requiring hemodialysis. ${ }^{16}$ Patients who present with renal insufficiency should be treated aggressively to try to normalize renal function as quickly as possible. An approach to management includes the evaluation of contributing factors and management of any reversible causes such as dehydration, hypercalcemia, and hyperuricemia. ${ }^{17}$ Patients should be counseled to drink a minimum of 2 liters of fluid per day to maintain a high urine output. For patients with renal dysfunction, choices of therapy should be made carefully dependent on the drug's metabolism. ${ }^{4,15}$

\section{Anemia}

Anemia is present in two thirds of patients at diagnosis, and almost all MM patients will experience anemia at some point during the course of their disease. ${ }^{4}$ Anemia may be caused by suppression of erythropoiesis by tumor-related cytokines, secondary to chemotherapy, renal insufficiency, and/or vitamin or iron deficiency. Anemia in most patients will improve as the underlying disease is treated. ${ }^{4}$

\section{Infections}

Because of decreased production of normal immunoglobulins, MM patients are at increased risk for infection. ${ }^{4}$ Patients should report fever and be evaluated with appropriate cultures and radiographic studies if they do present with fever.

\section{Hyperviscosity}

Patients with MM may also develop hyperviscosity syndrome and plasma exchange may be warranted for symptomatic patients. ${ }^{17}$ Less than $2 \%$ of MM patients present with hyperviscosity, and a few more will develop it after diagnosis. Clinical manifestations include mucosal hemorrhage; visual abnormalities; and neurologic and cardiac features such as heart failure, seizures, vertigo, and diplopia. Note that hyperviscosity is diagnosed when serum viscosity is greater than 4 centipoises; however, this may not be correlated with clinical manifestation. Treatment is aimed at preventing complications such as bleeding, loss of vision, and irreversible neurologic impairment. Chemotherapy should be started promptly once hyperviscosity has been stabilized. ${ }^{18}$

\section{Changes in the Standard of Care}

Recent advances in molecular cytogenetic, genomic, and proteomic studies of tumor cells and their normal counterparts have allowed for increased understanding of the pathogenesis of MM. They have also provided the basis for molecular prognostic classification, identified potential therapeutic targets, and provided the rationale for combining targeted therapies to increase tumor cell cytotoxicity, reduce nonspecific cytotoxicity, overcome conventional drug resistance, and improve patient outcome. ${ }^{6}$ Novel therapeutic agents that directly inhibit osteoclast differentiation are also being used to treat patients who have bone disease. ${ }^{8}$ Understanding the bone marrow microenvironment has played a role in the use and development of drugs such as thalidomide, lenalidomide, bortezomib, and bisphosphonates, and has changed the standard of care for patients. ${ }^{6}$ Ongoing studies are using oncogenomics to identify new therapeutic targets in MM cells and the bone marrow microenvironment. These findings will likely lead to next-generation therapies and serve as a model for identifying and validating new targeted therapeutics directed to improve the outcome of patients with other hematological malignancies. ${ }^{6}$

\section{A Look Ahead ...}

There are several clinical trials, ongoing and in various phases, that target cell surface molecules and cytokines. Antibodies that inhibit MM cell adhesion to fibronectin and BMSCs are also currently under evaluation in clinical trials for the treatment of MM. ${ }^{6}$ Other agents under investigation target cell surface receptors and/or the bone marrow microenvironment, including the FGFR-3 gene, farnesyltransferase inhibitors, mammalian target of rapamycin inhibitors, vascular endothelial growth factor, insulin growth factor 1 receptor inhibitors, and TNF-related, apoptosisinducing ligand. ${ }^{4}$ Further oncogenomic studies will allow for both patient selection and rational combination therapeutics. ${ }^{6}$

\section{DISCLOSURES}

Dr. Jagannath is a member of the Speakers' Bureaus for Millennium, The Takeda Oncology Company; Celgene Corporation; and Ortho Biotech Products, L.P.

\section{REFERENCES:}

1. Multiple Myeloma Research Foundation. Multiple Myeloma: Disease Overview. 2006. Available at: www.multiplemyeloma.org/downloads/about_ myeloma/Disease_Overview.pdf. Accessed August 15, 2008.

2. Kyle RA, Rajkumar SV. Multiple myeloma. N Engl J Med. 2004;351:1860-73.

3. Kuehl WM, Bergsagel PL. Multiple myeloma: evolving genetic events and host interactions. Nat Rev Cancer. 2002;2:175-87. 
4. Katzel JA, Hari P, Vesole DH. Multiple myeloma: charging toward a bright future. CA Cancer J Clin. 2007;57:301-18.

5. Greipp PR, San Miguel J, Durie BG, et al. International staging system for multiple myeloma. J Clin Oncol. 2005;23:3412-20.

6. Hideshima T, Mitsiades C, Tonon G, Richardson PG, Anderson KC. Understanding multiple myeloma pathogenesis in the bone marrow to identify new therapeutic targets. Nat Rev Cancer. 2007;7:585-98.

7. Abe M, Hiura K, Wilde J, et al. Role for macrophage inflammatory protein (MIP)-lalpha and MIP-lbeta in the development of osteolytic lesions in multiple myeloma. Blood. 2002;100:2195-202.

8. Joshua D. Pathophysiology-bone disease. Presented at: XIth International Myeloma Workshop; June 5-30, 2007; Kos, Greece. Available at: http://myeloma.org/main.jsp?source=link\&source_link_ id $=3039 \&$ type $=$ article $\&$ tab_id $=13 \&$ menu_id $=0 \& i d=2305$. Accessed March 14, 2008.

9. Zhan F, Sawyer J, Tricot G. The role of cytogenetics in myeloma. Leukemia. 2006; 20:1484-86.

10. Orlowski RZ. Initial therapy of multiple myeloma patients who are not candidates for stem cell transplantation. Hematology Am Soc Hematol Educ Program. 2006:338-47.

11. Chen L, Li J, Xu W, et al. Molecular cytogenetic aberrations in patients with multiple myeloma studied by interphase fluorescence in situ hybridization. Exp Oncol. 2007;29:116-20.
12. Auwerda JJ, Sonneveld P, de Maat M, et al. Prothrombotic coagulation abnormalities in patients with newly diagnosed multiple myeloma. Haematologica. 2007;92:279-80.

13. Lyman GH, Khorana AA, Falanga A, et al. American Society of Clinical Oncology guideline: recommendations for venous thromboembolism prophylaxis and treatment in patients with cancer. J Clin Oncol. 2007; 25:5490-505.

14. Lentzsch S, Ehrlich LA, Roodman GD. Pathophysiology of multiple myeloma bone disease. Hematol Oncol Clin North Am. 2007;21:1035-49.

15. Dimopoulos MA, Kastritis E, Rosinol L, Blade J, Ludwig H. Pathogenesis and treatment of renal failure in multiple myeloma. Leukemia. 2008:1-9, epub June 5, 2008.

16. International Myleoma Foundation. Multiple myeloma: renal involvement in multiple myeloma. Available at: http://myeloma.org/ main.jsp?newsletter_type $=$ detail\&type $=$ query\&tab_id $=18 \mathrm{menu}$ id0\&id=6\&newsletter_id=226. Accessed July 21, 2008.

17. Barosi G, Boccadoro M, Cavo M, et al. Management of multiple myeloma and related-disorders: guidelines from the Italian Society of Hematology, Italian Society of Experimental Hematology, and Italian Group for Bone Marrow Transplantation. Haematologica. 2004;89:717-41.

18. Schwartzberg L. Managed care considerations in the treatment of multiple myeloma. Managed Care Oncol. Spring 2007:14-16, 47. 